\title{
Enhanced electrocapacitive performance and high power density of polypyrrole/graphene oxide nanocomposites prepared at reduced temperature
}

\author{
Harish Mudila ${ }^{1}$, Varsha Joshi ${ }^{1}$, Sweta Rana ${ }^{1}$, Mohmd. Ghulam Haider Zaidi ${ }^{1, \AA}$ and Sarfaraz Alam ${ }^{2}$ \\ ${ }^{1}$ Department of Chemistry, G. B. Pant University of Agriculture \& Technology, Pantnagar, Uttarakhand-263145, India \\ ${ }^{2}$ Polymer Division, Defense Materials Research Development \& Establishment, (D.M.S.R.D.E.), PO. G.T. Road, Kanpur 208013, India
}

\author{
Article Info \\ Received 16 January 2014 \\ Accepted 24 May 2014 \\ *Corresponding Author \\ E-mail: mgh_zaidi@yahoo.com \\ Tel: +919411159853

\section{Open Access} \\ DOI: http://dx.doi.org/ \\ 10.5714/CL.2014.15.3.171 \\ This is an Open Access article distributed \\ under the terms of the Creative Commons \\ Attribution Non-Commercial License \\ (http://creativecommons.org/licenses/ \\ by-nc/3.0/) which permits unrestricted \\ non-commercial use, distribution, and \\ reproduction in any medium, provided \\ the original work is properly cited.
}

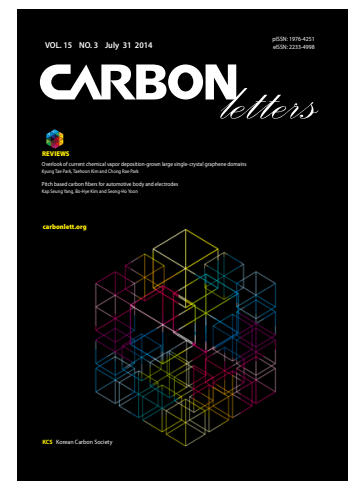

http://carbonlett.org

pISSN: 1976-4251

elSSN: 2233-4998

Copyright $\odot$ Korean Carbon Society

\begin{abstract}
An attempt was made to investigate the effect of the preparation temperature on the electrocapacitive performance of polypyrrole (PPY)/graphene oxide (GO) nanocomposites (PNCs). For this purpose, a series of PNCs were prepared at various temperatures by the cetyltrimethylammonium bromide-assisted dilute-solution polymerization of pyrrole in presence of GO (wt\%) ranging from 1.0 to 4.0 with ferric chloride as an oxidant. The formation of the PNCs was ascertained through Fourier-transform infrared spectrometry, X-ray diffraction spectra, scanning electron microscopy and simultaneous thermogravimetric-differential scanning calorimetry. The electrocapacitive performance of the electrodes derived from sulphonated polysulphone-bound PNCs was evaluated through cyclic voltammetry with reference to $\mathrm{Ag} /$ $\mathrm{AgCl}$ at a scan rate $(\mathrm{V} / \mathrm{s})$ ranging from 0.2 and 0.001 in potassium hydroxide $(1.0 \mathrm{M})$. The incorporation of GO into the PPY matrix at a reduced temperature has a pronounced effect on the electrocapacitive performance of PNCs. Under identical scan rates $(0.001 \mathrm{~V} / \mathrm{s})$, PNCs prepared at $10 \pm 1{ }^{\circ} \mathrm{C}$ render improved specific conductivity $(526.33 \mathrm{~F} / \mathrm{g})$ and power density $(731.19 \mathrm{~W} / \mathrm{Kg})$ values compared to those prepared at $30 \pm 1^{\circ} \mathrm{C}(217.69 \mathrm{~F} / \mathrm{g}, 279.43 \mathrm{~W} / \mathrm{Kg})$. PNCs prepared at $10 \pm 1{ }^{\circ} \mathrm{C}$ rendered a capacitive retention rate of $\sim 96 \%$ during the first 500 cycles. This indicates the excellent cyclic stability of the PNCs prepared at reduced temperatures for supercapacitor applications.
\end{abstract}

Key words: reduced temperature, preparation polypyrrole, graphene oxide, sulphonated polysulphone, nanocomposites, supercapacitors

\section{Introduction}

The development of novel polymer nanocomposites (PNCs) through the judicious combination of carbonaceous nanofillers with electrically conducting polymers for the conservation and storage of electrochemical energy has recently drawn great interest [1-3]. Carbonaceous nanofillers with outstanding electrical conductivity, good chemical stability, large surface area, high specific capacitance (Cs) and cycling stability improve the electrochemical performance of PNCs by giving them a long cycle life [2]. The supercapacitors derived from such PNCs are expected to provide a positive answer to the current demand for high-power energy storage systems with a reduced overpotential at high discharge rates [3]. Recently, a variety of PNCs based on graphene and its derivatives have been developed in combination with polyaniline $[4,5]$ and polypyrrole (PPY) $[4,6-8]$ in an effort to explore the next generation of electrochemical supercapacitors for electrochemical energy storage. In this context, PNCs derived from PPY in combination with graphene and graphene oxide (GO) in various proportions have recently been studied for the development of electrochemical energy storage devices [6,9-11]. In the preparation of such materials, the temperature plays a crucial role in their electronic conductivity. Recent studies have revealed that polymerization at a 


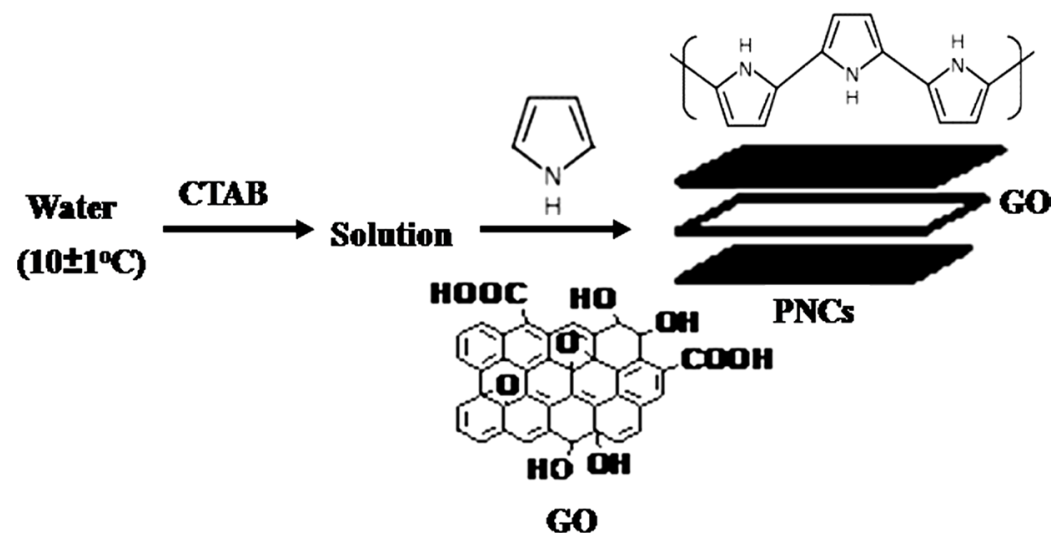

Fig. 1. Steps involved in the preparation of high-power-density polymer nanocomposites (PNCS) at reduced temperatures. CTAB: cetyltrimethylammonium bromide.

low temperature liberates PPY nanoparticles [12] with improved specific and electrochemical conductivities [13-19].

The present paper deals with an investigation of the effect of the preparation temperature on the electrocapacitive performance and power density of PPY/GO nanocomposites (PNCs). For this purpose, a series of PPY-GO nanocomposites (PNCs) was prepared at $30 \pm 1{ }^{\circ} \mathrm{C}$ and $10 \pm 1^{\circ} \mathrm{C}$, through the cetyltrimethylammonium bromide (CTAB) assisted dilute-solution polymerization of pyrrole in the presence of different concentrations of $\mathrm{GO}(\mathrm{wt} \%)$ ranging from 1.0 to 4.0 with ferric chloride as an oxidant. The investigation demonstrates that PNCs prepared in the presence of a low percentage of $\mathrm{GO}$ at temperatures of $10 \pm 1^{\circ} \mathrm{C}$ rendered a dramatic enhancement in their specific capacitance over those prepared at $30 \pm 1{ }^{\circ} \mathrm{C}[20-23]$. The prepared PPY and respective PNCs were characterized through Fourier-transform infrared (FT-IR) spectrography, their X-ray diffraction (XRD) spectra, scanning electron microscopy (SEM) and simultaneous thermogravimetry-differential scanning calorimetry (TG-DSC). Their supercapacitance was investigated through cyclic voltammetry in potassium hydroxide $(\mathrm{KOH}, 1.0 \mathrm{M})$. The investigation reveals that PNCs prepared at $10 \pm 1{ }^{\circ} \mathrm{C}$ display better electrochemical performance and may serve as high-power cathode materials with stable supercapacitance up to 500 cycles at a scan rate of $0.1 \mathrm{~V} / \mathrm{s}$ over those prepared at $30 \pm 1{ }^{\circ} \mathrm{C}$

\section{Materials and Methods}

\subsection{Starting materials}

Polysulfone (PU, Mn; $\left.16 \times 10^{3}\right)$, pyrrole $(>99 \%)$, CTAB $(>99 \%)$ and chlorosulfonic acid $(>99 \%)$ were procured from Sigma Aldrich. The graphite flakes used had an average particle size of $500 \mu \mathrm{m}$. Other chemicals and solvents were procured from S.D. Fine Chemicals, India. Sulfonated polysulphone (SPS) was prepared through the chlorosulfonation of PU and served as binder for the electrode materials [23]. GO was prepared through a modified Hummers method [24]. In this procedure, graphite flakes $(5 \mathrm{mg})$ were digested into sulphuric acid $(120 \mathrm{~mL}, \mathrm{~d}=1.84 \mathrm{~g} / \mathrm{cc})$ for $10 \mathrm{~min}$ at $-5^{\circ} \mathrm{C}$ and were subsequently oxidized in the presence of potassium permanganate $(15 \mathrm{~g})$ for $30 \mathrm{~min}$. The contents were diluted with deionized water (200 $\mathrm{mL})$ at $35 \pm 1{ }^{\circ} \mathrm{C}$, further oxidized with hydrogen peroxide $(30 \%$, $50 \mathrm{~mL}$ ) and re-diluted with warm deionized water $(450 \mathrm{~mL})$. This has afforded a slurry that was subsequently treated with hydrochloric acid $(5 \%, 50 \mathrm{~mL})$, where the grey-black $\mathrm{GO}$ was separated. The GO was isolated through filtration and successively washed with deionized water to remove the salt impurity contaminants. The purified GO was dried at $45 \pm 1^{\circ} \mathrm{C}$ for $48 \mathrm{~h}$.

\subsection{Preparation of the PNCs}

A pair from a series of PPY-GO nanocomposites (PNCs) was separately prepared at ambient $\left(30 \pm 1^{\circ} \mathrm{C}\right)$ and reduced temperatures $\left(10 \pm 1^{\circ} \mathrm{C}\right)$ in a thermostatically controlled three-necked glass reactor equipped with a mechanical stirrer, a thermometer and a dropping funnel [25]. The reactor was charged with an aqueous suspension consisting of pyrrole $(0.28 \mathrm{M}, 30 \mathrm{~mL})$, requisite concentration ( $\mathrm{wt} \%$ ) of $\mathrm{GO}$ ranging from 1.0 to 4.0 , and CTAB (1.145 g) as a stabilizer. The dropping funnel was charged with a solution of $\mathrm{FeCl}_{3}\left(30 \mathrm{~mL}, 1.85 \times 10^{-2} \mathrm{~mol} / \mathrm{dL}\right)$. The polymerization of pyrrole was initiated through the addition of a solution of $\mathrm{FeCl}_{3} @ 1 \mathrm{~mL} / \mathrm{min}$ to the suspension under constant stirring@600 rpm for 24 h. PNCs were isolated through centrifugation of the suspension at $6000 \mathrm{rpm}$ for $10 \mathrm{~min}$, followed by filtration, successive washing with deionized water, and drying at $50 \pm 1{ }^{\circ} \mathrm{C} / 400 \mathrm{mmHg}$ for $8 \mathrm{~h}$. PPY was also prepared under identical reaction conditions.

\subsection{Preparation of the electrodes}

A commercially available $316-\mathrm{SS}$ sheet was cut into a $1 \mathrm{~cm}^{2}$ area and finished with emery paper (mesh size 320600). It was then de-greased with acetone and subjected to surface oxidation at $50 \pm 1{ }^{\circ} \mathrm{C}$ for $1 \mathrm{~h}$. An electroactive material $(65 \mathrm{mg})$ along with graphite $(10 \mathrm{mg})$ was mixed with a solution of SPS $(5 \mathrm{~g}$ / dL) in N-methyl pyrrolidone. The contents were ultrasonicated for $15 \mathrm{~min}$ and applied $(50 \mu \mathrm{L})$ over a SS substrate. The treated substrate was dried at room temperature for $2 \mathrm{~h}$ and then at $100^{\circ} \mathrm{C} / 400 \mathrm{mmHg}$ for $48 \mathrm{~h}$. This afforded cathodes with a mass thickness of electroactive materials by $5 \pm 1 \mathrm{mg}$ over the 316 -SS substrate [25]. 


\subsection{Characterization}

The FT-IR spectra were recorded on a Thermo Nicolet FTIR spectrophotometer using $\mathrm{KBr}$ pellets. XRD patterns of powdered samples were recorded at room temperature by a RigakuGeigerflex X-ray diffractometer using $\mathrm{Cu}-\mathrm{K} \alpha$ radiation. SEM images of the gold-coated samples were imaged over JEOL (JSM-6610 LV) with a beam voltage $5 \mathrm{KV}$ at $2.7 \mathrm{KX}$ at $5 \mu \mathrm{m}$. The average particle size was estimated using the Debye-Scherrer formula:

$$
\mathrm{D}=0.9 \lambda / B \cos \theta
$$

Here, ' $\lambda$ ' is wavelength of X-ray $(0.1541 \mathrm{~nm})$, ' $\beta$ ' is the full width at half maximum, ' $\theta$ ' is the diffraction angle and ' $D$ ' is the particle diameter size. The value of $d$ (the interplanar spacing between the atoms) is calculated using Bragg's Law:

$$
2 \mathrm{~d} \sin \theta=\mathrm{n} \lambda
$$

TG data were recorded over thermogravimetric analysis (TGA)-50H with a sample weight ranging from 2.16 to $6.64 \mathrm{mg}$ under $\mathrm{N}_{2}$ at a rate of $30 \mathrm{~mL} / \mathrm{min}$ from $\sim 20^{\circ} \mathrm{C}$ to $600^{\circ} \mathrm{C}$. DSC data were recorded on a DSC-60 device with a flow rate of $30 \mathrm{~mL} /$ min from $\sim 25^{\circ} \mathrm{C}$ to $275^{\circ} \mathrm{C}$

The electrochemical characteristics of the samples were investigated using an IVIUM potentiostat-galvanostat Netherlands BV using a three-electrode cell assembly with reference to an $\mathrm{Ag} / \mathrm{AgCl}$ electrode, a $\mathrm{Pt}$ foil with a $1 \mathrm{~cm}^{2}$ area as counter electrode, and a commercially available 316-SS electrode as a working electrode. The cyclic voltammograms (CVs) were recorded at voltages ranging from -0.1 to $-0.6 \mathrm{~V}$ at scan rates $(\mathrm{V} / \mathrm{s})$ of $0.001-0.20$ at $10 \mathrm{~mA}$ in $\mathrm{KOH}(1 \mathrm{M})$. The specific capacitance (Cs) of the active materials was calculated from the voltammetric charges by the $\mathrm{CV}$ curve with the equation

$$
\mathrm{Cs}=\mathrm{q}_{\mathrm{a}}+\left|\mathrm{q}_{\mathrm{c}}\right| / 2 \mathrm{~m} \Delta \mathrm{V} \text {, }
$$

where " $\mathrm{q}_{\mathrm{a}}$ " and " $\mathrm{q}_{\mathrm{c}}$ " are the voltammetric charges on the anodic and cathodic scans, respectively, in the capacitive potential region $(\Delta \mathrm{V})$, and " $\mathrm{m}$ " is the mass of the active material. The energy density (E) and power density (P) for PPY and PNCs were estimated, respectively, through the following equations:

$$
\begin{aligned}
& \mathrm{E}=\operatorname{Cs}(\Delta \mathrm{V})^{2} / 2 \\
& \mathrm{P}=(\mathrm{E} / t)
\end{aligned}
$$

Here, "Cs" is the specific capacitance, $\Delta \mathrm{V}$ is the applied initial voltage and " $\mathrm{t}$ " is the corresponding discharge time in hours.

\section{Results and Discussion}

\subsection{FT-IR spectra}

The formation of PPY, GO and respective the PNCs was clearly reflected through the FT-IR spectra (Fig. 2). Graphite shows wave numbers $\left(\mathrm{cm}^{-1}\right)$ corresponding to the valence vibra-

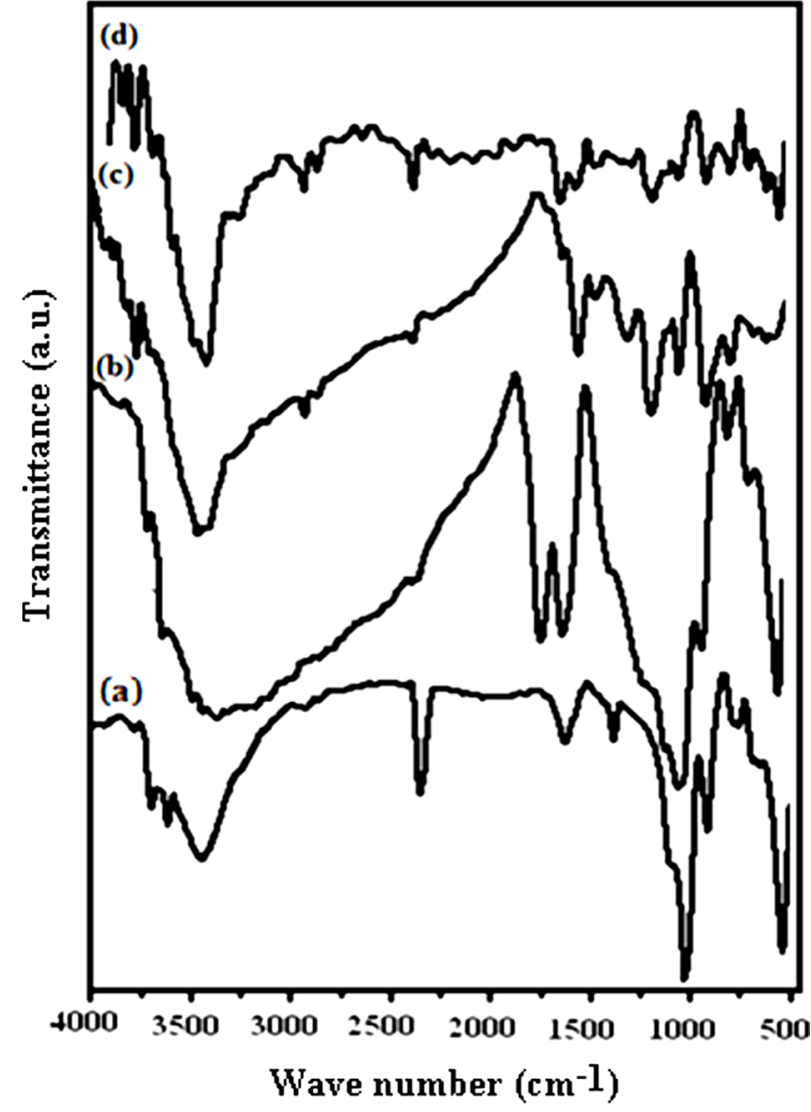

Fig. 2. Fourier-transform infrared spectra of (a), graphite (b), graphene oxide (c), polypyrrole and (d) [IV].

tion of -OH (3750), vO-H due to the adsorbed moisture (3447), $\delta \mathrm{O}-\mathrm{H}$ merged with $\mathrm{vC}=\mathrm{C}(1628)$, the adsorbed carbon dioxide (2354) flexural vibration peak of $\mathrm{CH}_{2}$ (1467), and aromatic structures (880 to 750$)[26,27]$. GO indicates characteristic absorptions at $\sim 3333 \mathrm{~cm}^{-1}$ (vO-H), 1723 (v COOH), 1613 (remaining $\mathrm{sp}^{2}$ character), 1378 (v C-O-C), 1221 (C-O for oxirane) and 1033 (vC-OH) (Fig. 2b) [26]. PPY shows characteristic FT-IR absorptions corresponding to $v \mathrm{~N}-\mathrm{H}$ (3450) [28], $v \mathrm{C}-\mathrm{H}$ (2925), $v_{\text {sym }} \mathrm{C}=\mathrm{C}(1,652), v \mathrm{C}-\mathrm{C}(1465), v \mathrm{C}-\mathrm{N}(1550)$ [29], $v \mathrm{C}=\mathrm{C}(1564)$ representing the formation of 2,5-substituted PPY $[28,30], v \mathrm{C}-\mathrm{H}$ in-plane deformation (1397) [28] and $v \mathrm{C}-\mathrm{H}$ out-of-plane deformation (672.4) [31]. The peak at 1050 is attributed to $\mathrm{C}-\mathrm{H}$ deformation. The broadband at 1300 corresponds to the inplane deformation of C-H and C-N. The peaks near 1190 and 922 represent the doping state of PPY with $\mathrm{Fe}^{3+}$ [32] (Fig. 2c). PNCs prepared at $10 \pm 1{ }^{\circ} \mathrm{C}$ show absorptions at 3330 (vO-H), 3430 (vN-H), 1615 ( $\mathrm{sp}^{2}$ character), 1376 (vC-O-C), 1215 (vC-O oxirane), $1545\left(\mathrm{v}_{\mathrm{as}} \mathrm{C}-\mathrm{N}\right.$ ring), 1185,916 (vC-N) corresponding to the doping state of PPY with $\mathrm{Fe}^{3+}, 1460$ (vC-C ring), and 1300 ( $\delta \mathrm{C}-\mathrm{H}$ in-plane) [32] (Fig. 2d). It is important to note that all the major peaks corresponding to PPY were shifted towards a lower wave number in the PNCs prepared at $10 \pm 1^{\circ} \mathrm{C}$. This may be related to the constrained growth and restricted modes of the vibrations in the PPY in the presence of GO due to the л-л stacking between the GO layers and the aromatic PPY rings [6]. 


\subsection{Microstructure}

Fig. 3 shows the XRD patterns of graphite (a), GO (b), PPY (c) and [IV] (d). Graphite shows an XRD pattern of $2 \theta=27.04^{\circ}$, corresponding to its highly organized layer structure with an interlayer distance of $0.33 \mathrm{~nm}$ along the (002) orientation. In addition, $2 \theta=44.8$ and $55^{\circ}$, representing the (100) and (004) planes of graphite [33] (Fig. 3a) were noted. After chemical oxidation, the $(002)$ peak of graphite was shifted to a lower angle at $2 \theta=$ $10.80^{\circ}$, indicating an increase in the d-spacing from $0.33 \mathrm{~nm}$ to $0.82 \mathrm{~nm}$ (Fig. 3b). Such an increased interlayer distance between the adjacent carbon basal planes is attributed to the intercalation of oxygen functional groups into the carbon layer structure of GO. Thus, from the XRD pattern, the original graphite structure was almost completely oxidized into GO [34,35]. PPY shows a broad characteristic peak at $2 \theta=27.26^{\circ}(\mathrm{d}=0.33 \mathrm{~nm})$, implying an amorphous structure [36]. With the concentration of GO, a regular increase in the gallery spacing of the PPY in the PNCs prepared at $10 \pm 1{ }^{\circ} \mathrm{C}$ was observed, ranging from 0.33 to 0.34 with a shift in $2 \theta=27.05^{\circ}$ to $26.43^{\circ}$ (Table 1). Such an increase in the gallery spacing of PPY in the respective GO is attributed to their lamination over the graphitic surface of GO $[34,35]$. The broad peak which appeared at $2 \theta=26.43^{\circ}$ is attributed to the amorphous characteristic of the PNCs [36]. Fig. 4a shows a SEM image of GO which reveals a crumpled and

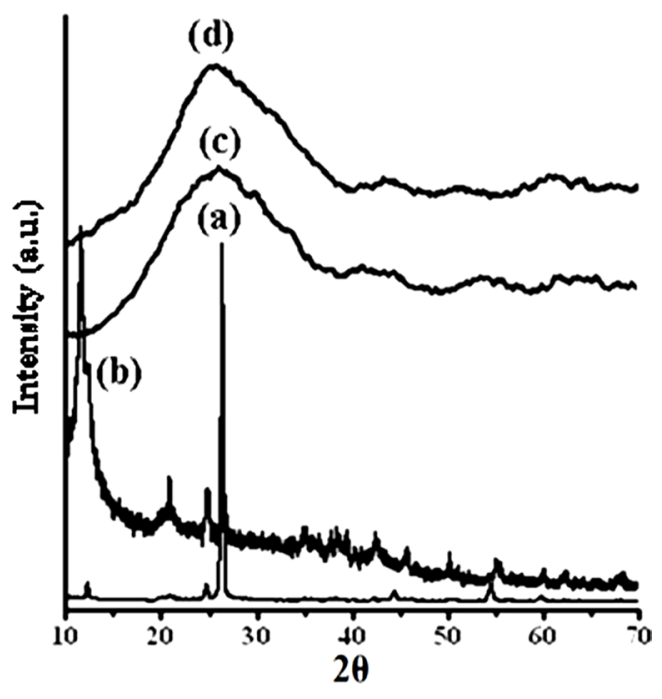

Fig. 3. X-ray diffraction spectra of (a) graphite, (b) graphene oxide, (c) polypyrrole and (d) [IV]. rippled structure which was the result of deformation upon the exfoliation and restacking during the processes of the oxidation of graphite [37,38]. Clear phase separation is observed in the case of PPY, and the deposited surface indicates specific porous
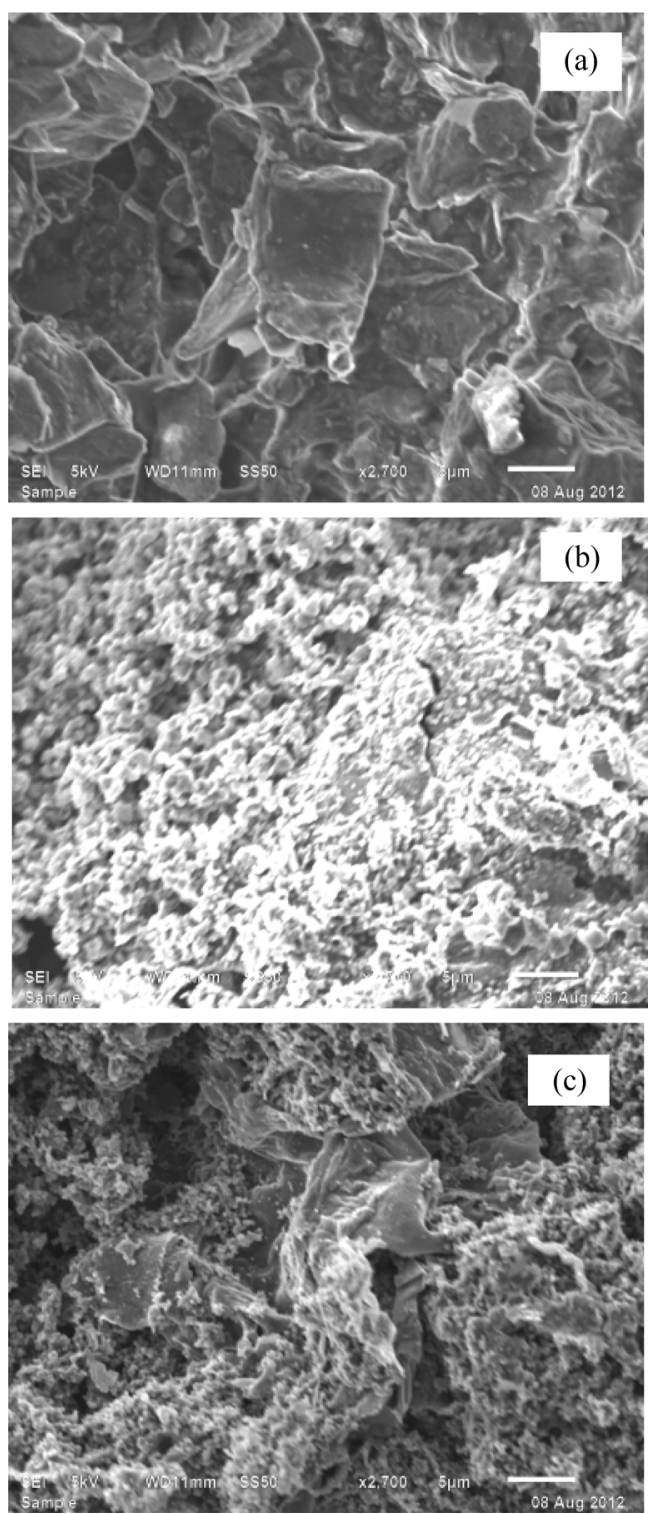

Fig. 4. Scanning electron microscopy images of (a) graphene oxide, (b) polypyrrole and (c) [IV] at $5 \mu \mathrm{m}, 2.7 \mathrm{KX}$.

Table 1. Effect of the composition of pncs on the grain size of PNCs prepared at $10 \pm 1^{\circ} \mathrm{C}$

\begin{tabular}{cccccc} 
PNCs & $2 \theta$ of the intense peak (deg) & $\theta$ of the intense peak (deg) & FWHM ( $\beta$ ) of intense peak radians & Grain size (D) nm & d-spacing $(\mathrm{nm})$ \\
\hline$[\mathrm{I}]$ & 27.04 & 13.52 & 0.0063 & 22.70 & 0.33 \\
{$[\mathrm{III}]$} & 10.80 & 13.44 & 0.0066 & 21.59 & 0.82 \\
{$[\mathrm{III}]$} & 26.69 & 13.35 & 0.0067 & 21.28 & 0.33 \\
{$[\mathrm{IV}]$} & 26.43 & 13.22 & 0.0074 & 19.24 & 0.34 \\
\hline
\end{tabular}

PNC: polymer nanocomposites, FWHM: full width at half maximum. 
gaps and pores as well as spheroid grain-like structures (Fig. 4b). Such a spherical morphology accounts for the satisfactory electrochemical activity of PPY [39]. The stark contrast between the respective images clearly shows that new PNCs were materialized through the intercalation of PPY in the gallery spacing of GO [21] (Fig. 4c).

\subsection{Thermal analysis}

Fig. 5 shows the TGA curves of PPY and [IV] prepared at $10 \pm 1{ }^{\circ} \mathrm{C}$. This figure demonstrates that the thermal stability of [IV] is significantly higher than that of PPY in the range of 40 to $600^{\circ} \mathrm{C}$. Owing to its hygroscopic nature, the $\mathrm{W}_{\mathrm{L}}(\mathrm{wt} \%)$ of 6.67 at $100^{\circ} \mathrm{C}$ is attributed to the moisture content associated with PPY due to the evaporation of residual water. Intercalation of various concentrations (wt\%) of GO ranging from 1.0 to 4.0 into PPY

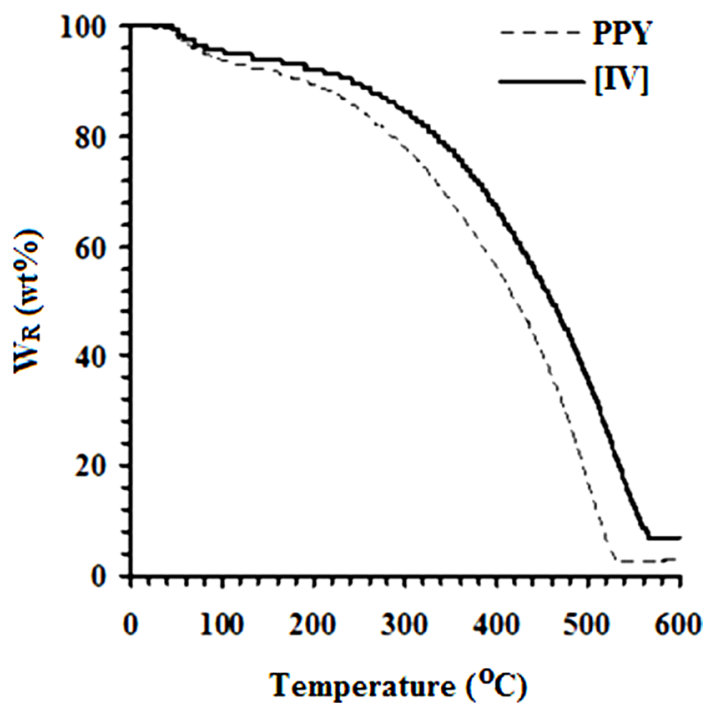

Fig. 5. Thermogravimetric analysis curve of polypyrrole (PPY) and [IV] prepared at $10 \pm 1^{\circ} \mathrm{C}$.

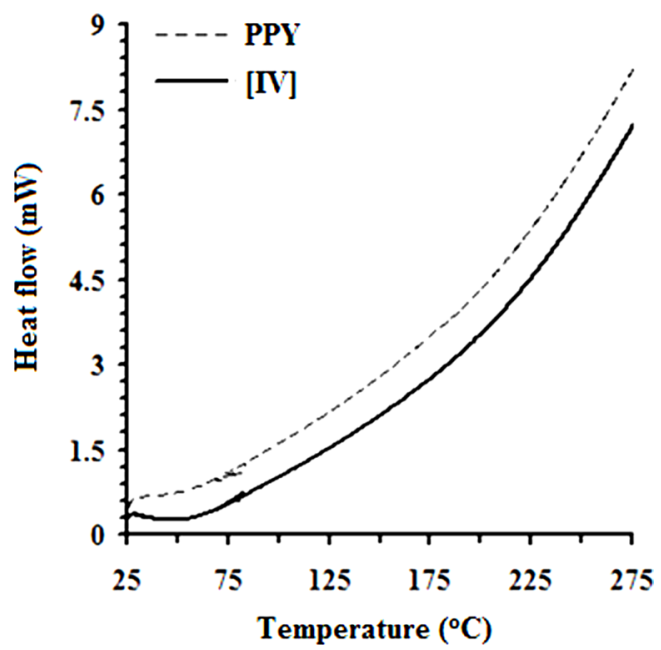

Fig. 6. Differential scanning calorimetry scans of polypyrrole (PPY) and [IV] prepared at $10 \pm 1^{\circ} \mathrm{C}$. afforded PNCs with a marginal moisture content ranging from 5.60 from 5.05. With an increase in the temperature, the weight loss in PYY was appeared at a TG onset $\left({ }^{\circ} \mathrm{C}\right)$ of 288.87 , leaving a $\mathrm{Wr}(\mathrm{wt} \%)$ of 93.33 [40]. The TG onset of PNCs was gradually increased in the range of 299.45 to 352.84 with the concentration of GO. The decomposition of PPY was ended with the TG endset $\left({ }^{\circ} \mathrm{C}\right)$ at 525.34 with complete volatilization. The steady increase in the $\mathrm{Wr}(\mathrm{wt} \%)$ of PNCs in the temperature range between 100 to $250^{\circ} \mathrm{C}$ is attributed to the removal of oxygenated functional groups viz., $\mathrm{CO}$ and $\mathrm{CO}_{2}$. Decomposition of $50 \%$ of the PNCs occurs around $\sim 450^{\circ} \mathrm{C}$ with a sudden weight loss in the range of 400 to $550^{\circ} \mathrm{C}$ due to decomposition of PPY and oxygen-bearing functionalities over GO. Such a sudden weight loss in PNCs was terminated at the TG endset $\left({ }^{\circ} \mathrm{C}\right)$ ranging from 532.21 to 571.54 and leaving char residue (wt\%) ranging from 2.79 to 10.10 . The DSC curves in Fig. 6 reveal a remarkable increase in the $\mathrm{Tg}\left({ }^{\circ} \mathrm{C}\right)$ of PNCs ranging from 26.14 to 69.08 with the concentration of GO. The weak interaction and more ordered arrangement in the matrix of the polymer and the oxide (GO) cause a regular increment in the Tg of PNCs with the concentration of GO, as compared to the PPY. The exothermic peaks in the DSC curves of PPY and PNCs were absent, indicating their thermally stable nature. Such thermal stability associated with PNCs is attributed to the orderliness of the GO intercalates into the macromolecules of PPY, as supported by XRD and SEM analyses. The deflagration of GO occurs at high temperature; therefore, the compact and ordered arrangements of GO in the molecular chains of the electroactive polymer function as a barrier to heat transport in the PNCs, thus preventing the deflagration of the polymer and pronounced thermal stability in the PNCs [25].

\subsection{Electrochemical behavior}

The electrochemical behavior of PPY and the respective nanocomposites was clearly indicated through cyclic voltammetry, which shows quasi-rectangular scans. The cyclic voltammogram reveals the proportionality of the peak current densities with the scan rates, indicating their high electroactive nature and reversible redox behavior. Their anodic and cathodic peak potentials were nearly independent of the scan rates. The voltammogram indicates the cycleability of both materials between the conducting (oxidized) and insulating (neutral) states with insignificant decomposition due to their high electrochemical stability. The peak potential shift in the CV may be responsible for the slow ion diffusion or interfacial charge transfer processes due to the slow heterogeneous electron transfer, the effects of local rearrangements of the polymer chains, and the slow mutual transformations of various electronic species [41]. Fig. 7a shows the $\mathrm{CV}$ of PPY and [IV] prepared in the presence of GO (4.0 $\mathrm{wt} \%)$ at $30 \pm 1$ and $10 \pm 1{ }^{\circ} \mathrm{C}$ at a scan rate $(\mathrm{V} / \mathrm{s})$ of 0.1 in a potential window of -0.1 to $-0.6 \mathrm{~V}$. The $\mathrm{CV}$ shows continuous increase in the peak current in the order of PPY followed by PNCs prepared at $30 \pm 1$ and $10 \pm 1^{\circ} \mathrm{C}$, respectively [41].

A regular increase in the peak currents for PPY and PNCs was observed in the potential range from -0.6 to -0.1 with the scan rate. Such an increase in the peak current was more pronounced for PNCs prepared at $10 \pm 1{ }^{\circ} \mathrm{C}$ over those prepared at $30 \pm 1{ }^{\circ} \mathrm{C}$ [13-19] (Fig. 7a). The effects of the concentration of GO con- 


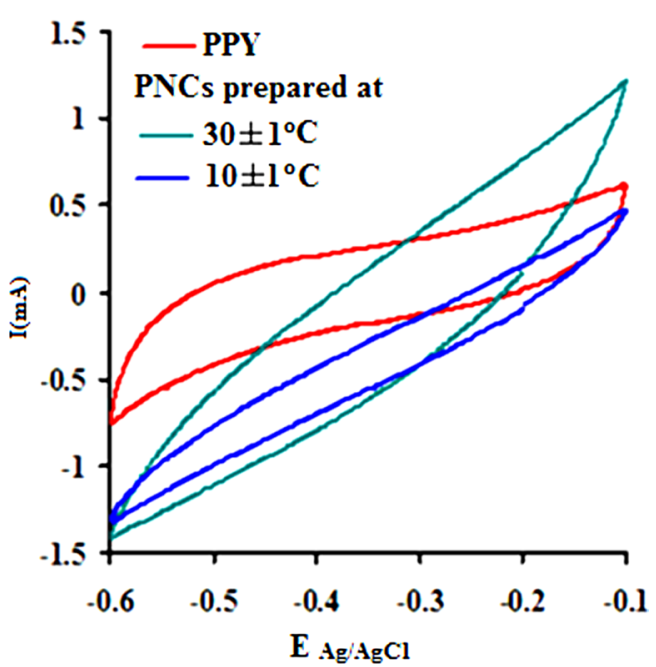

Fig. 7a. Cyclic voltammograms at a scan rate of $0.1 \mathrm{~V} / \mathrm{s}$ for polypyrrole (PPY) and polymer nanocomposites (PNCs) prepared at $10 \pm 1^{\circ} \mathrm{C}$.

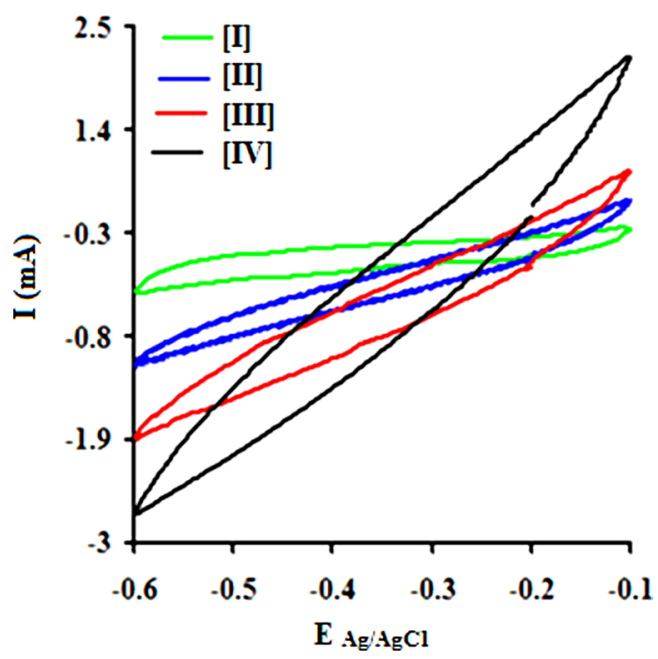

Fig. 7b. Cyclic voltammograms at a scan rate of $0.2 \mathrm{~V} / \mathrm{s}$ for polymer nanocomposites prepared at $10 \pm 1^{\circ} \mathrm{C}$.

tributed to the peak current of the PNCs prepared at $10 \pm 1{ }^{\circ} \mathrm{C}$ at a constant scan rate (Fig. 7b). Fig. 7c represents a comparison of the specific capacitance of PPY $(8.35-109.33 \mathrm{~F} / \mathrm{g})$ with GO $(17.68-352.32 \mathrm{~F} / \mathrm{g})$, which was judged to be higher later at all scan rates $(0.001-0.2 \mathrm{~V} / \mathrm{s})$. With an increase in the concentration of GO, a regular increase in the cathodic and anodic currents was observed. This contributed to a corresponding increase in the Cs of the PNCs prepared at $30 \pm 1^{\circ} \mathrm{C}$ and $10 \pm 1^{\circ} \mathrm{C}$. A comparative study of the effect of the temperature along with the scan rate reveals that all of the PNCs prepared at $10 \pm 1{ }^{\circ} \mathrm{C}$ show a remarkable increase in the specific capacitance (223.73-526.43 $\mathrm{F} / \mathrm{g}$ ) over those prepared at $30 \pm 1{ }^{\circ} \mathrm{C}(109.02-217.69 \mathrm{~F} / \mathrm{g})$ (Fig. $7 \mathrm{~d})$. With an increase in the concentration of GO, a regular increase in the $\mathrm{Cs}(\mathrm{F} / \mathrm{g})$ of PNCs was observed at all individual scan rates, which gradually declined with a regular increase in the scan rate. The decrease in Cs at an increasing scan rate in

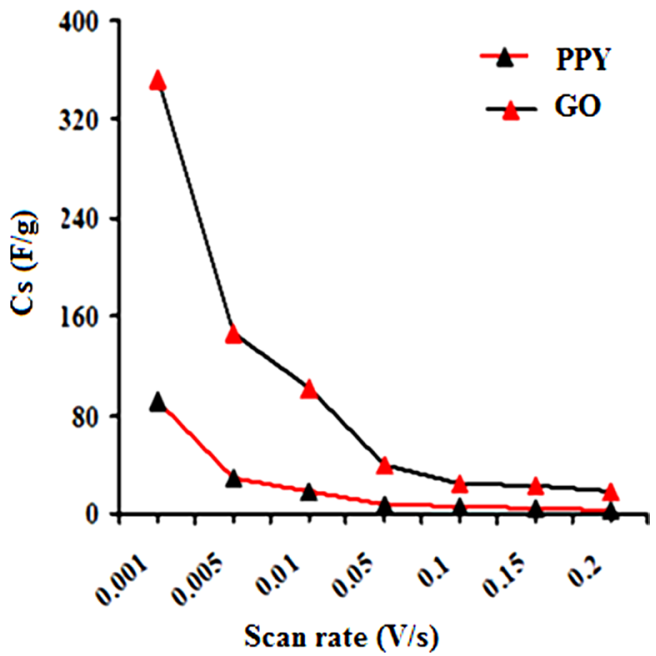

Fig. 7c. Effect of the scan rate on $\mathrm{Cs}$ of graphene oxide (GO) and polypyrrole (PPY).

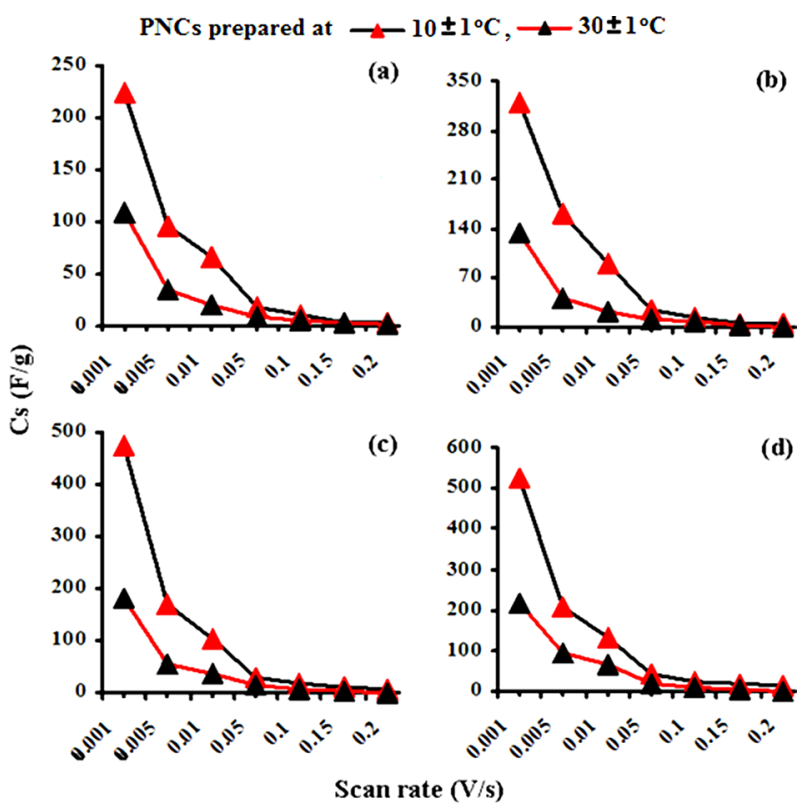

Fig. 7d. Effect of the scan rate on the specific conductance values of (a) [I], (b) [II], (c) [III] and (d) [IV]. PNC: polymer nanocomposites.

$\mathrm{CV}$ is attributed to the restricted diffusion of the charge, which induces a reduction in Cs and a high power density of PNCs. The energy $(\mathrm{Wh} / \mathrm{Kg})$ and power densities $(\mathrm{W} / \mathrm{Kg})$ rendered by PPY were 3.79 and 136.44 , respectively. The energy density of the [IV] prepared at $30 \pm 1$ and $10 \pm 1{ }^{\circ} \mathrm{C}$ were on the order of 7.56 and 18.28 , and 279.43 and 731.19 , respectively.

Fig. 7e shows charging-discharging curves of [IV] prepared at $30 \pm 1$ and $10 \pm 1{ }^{\circ} \mathrm{C}$ recorded in the voltage range from $-0.6 \mathrm{~V}$ to $-0.1 \mathrm{~V}$ at an applied current density of $10 \mathrm{~mA} / \mathrm{cm}$. The charge/ discharge curves exhibit reversible characteristics without an apparent deviation in each cycle. The charge/discharge curves are nearly linear along the total range of potential with constant 


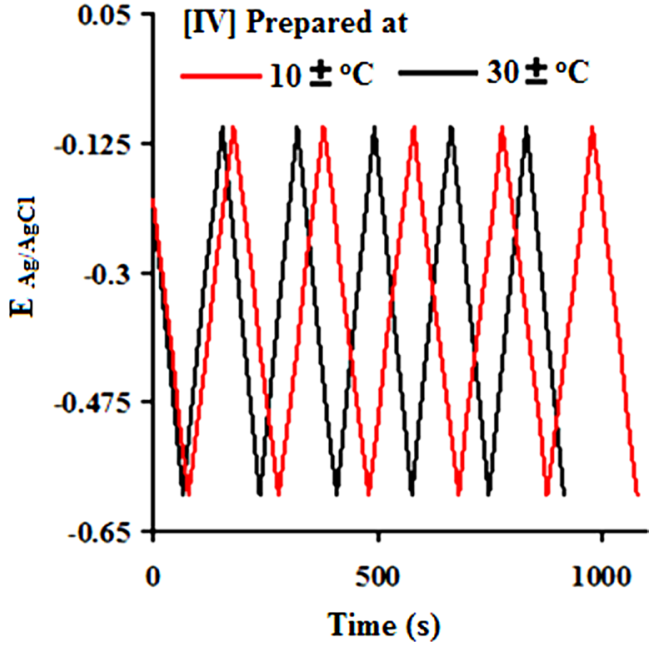

Fig. 7e. Charge-discharge curves at $10 \mathrm{~mA} / \mathrm{cm}$ of [IV].

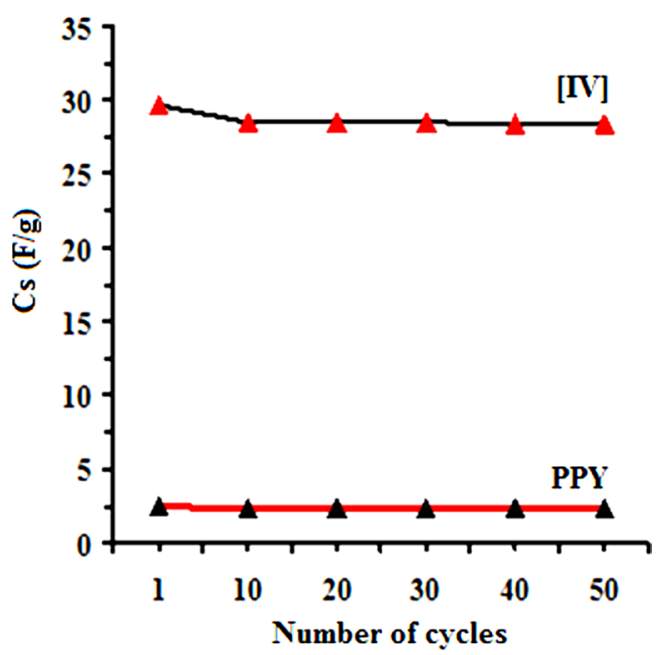

Fig. 7f. Effect of the number of cycles on the Cs values ofpolypyrrole (PPY) and [IV] prepared at $10 \pm 1^{\circ} \mathrm{C}$.

slopes, showing perfect capacitive behavior. This suggests better electrochemical stability of the electrodes derived from PNCs which were prepared at $10 \pm 1{ }^{\circ} \mathrm{C}$. The capacitive decrease of $\sim 4 \%$ during the first 500 cycles at a $0.1 \mathrm{~V} / \mathrm{s}$ (Fig. $7 \mathrm{f}$ ) indicates the excellent cyclic stability of the PNCs for supercapacitor applications. Thus, the introduction of $\mathrm{GO}$ at a low temperature of $10 \pm 1{ }^{\circ} \mathrm{C}$ had afforded PNCs with improved specific conductivity and power density, making them suitable for supercapacitor applications.

\section{Conclusion}

CTAB-assisted dilute-solution polymerization of pyrrole at various temperatures in the presence of varying concentrations of $\mathrm{GO}$ (wt\%) ranging from 1.0 to 4.0 with $\mathrm{FeCl}_{3}$ as an oxidant afforded a series of PPY/GO nanocomposites (PNCs).
Fourier-transform infrared spectrography reveals the formation of PNCs. This study, based on the X-ray diffraction spectra and scanning electron microscopy, indicates the intercalation of GO into a PPY matrix. The electrocapacitive performance of PNCs prepared at various temperatures was investigated through cyclic voltammetry at scan rates $(\mathrm{V} / \mathrm{s})$ ranging from 0.2 to 0.001 in $\mathrm{KOH}(1.0 \mathrm{M})$. With an increase in the concentration of GO, the PNCs prepared at $10 \pm 1{ }^{\circ} \mathrm{C}$ show a regular increase in their thermal stability, electrochemical supercapacitance (Cs), and power densities compared to PPY and PNCs prepared at $30 \pm$ $1^{\circ} \mathrm{C}$. With an increase in the scan rate, a proportionate increase in the peak current densities of PNCs with cycleability of the redox behavior without significant decomposition was observed. Their anodic and cathodic peak potentials were nearly independent of the scan rates. PPY and GO showed respective Cs (F/g) values in the ranges of 109.33-8.35 and 352.32-17.68, respectively. The highest Cs of 526.33 at $0.001 \mathrm{~V} / \mathrm{s}$ was shown by [IV] prepared at $10 \pm 1^{\circ} \mathrm{C}$, with stability up to 500 cycles. The energy density $(\mathrm{Wh} / \mathrm{Kg}$ ) and power density $(\mathrm{W} / \mathrm{Kg}$ ) of [IV] were 18.28 and 731.19 , respectively, which were much higher than the corresponding nanocomposite prepared at $30 \pm 1^{\circ} \mathrm{C}$.

\section{Acknowledgements}

The financial support granted by the Defense Research Development Organization, India vides Grant No. ERIP/ ER/0703649/M/01/1092 to G.B. Pant University of Agriculture \& Technology and the DST Inspire fellowships vide Grant No. IF 110513 awarded to Harish Mudila are acknowledged.

\section{References}

[1] Wang G, Zhang L, Zhang J. A review of electrode materials for electrochemical supercapacitors. Chem Soc Rev, 41, 797 (2012). http://dx.doi.org/10.1039/c1cs15060j.

[2] Huang Y, Liang J, Chen Y. An overview of the applications of graphene-based materials in supercapacitors. Small, 8, 1805 (2012). http://dx.doi.org/10.1002/smll.201102635.

[3] Fang Y, Luo B, Jia Y, Li X, Wang B, Song Q, Kang F, Zhi L. Renewing functionalized graphene as electrodes for high-performance supercapacitors. Adv Mater, 24, 6348 (2012). http://dx.doi. org/10.1002/adma.201202774.

[4] Ramya R, Sivasubramanian R, Sangaranarayanan MV. Conducting polymers-based electrochemical supercapacitors: progress and prospects. Electrochim Acta, 101, 109 (2013). http://dx.doi. org/10.1016/j.electacta.2012.09.116.

[5] Shulga YM, Baskakov SA, Abalyaeva VV, Efimov ON, Shulga NY, Michtchenko A, Lartundo-Rojas L, Moreno-R LA, CabañasMoreno JG, Vasilets VN. Composite material for supercapacitors formed by polymerization of aniline in the presence of graphene oxide nanosheets. J Power Sources, 224, 195 (2013). http://dx.doi. org/10.1016/j.jpowsour.2012.09.105.

[6] Sahoo S, Dhibar S, Hatui G, Bhattacharya P, Das CK. Graphene/ polypyrrole nanofiber nanocomposite as electrode material for electrochemical supercapacitor. Polymer, 54, 1033 (2013). http:// dx.doi.org/10.1016/j.polymer.2012.12.042.

[7] Lai L, Wang L, Yang H, Sahoo NG, Tam QX, Liu J, Poh CK, Lim 
SH, Shen Z, Lin J. Tuning graphene surface chemistry to prepare graphene/polypyrrole supercapacitors with improved performance. Nano Energy, 1, 723 (2012). http://dx.doi.org/10.1016/j. nanoen.2012.05.012

[8] Wang J, Xu Y, Zhu J, Ren P. Electrochemical in situ polymerization of reduced graphene oxide/polypyrrole composite with high power density. J Power Sources, 208, 138 (2012). http://dx.doi. org/10.1016/j.jpowsour.2012.02.018.

[9] Huh DS, Basavaraja C, Kim WJ. Polypyrrole/graphene oxide composites with improved conductivity and solubility. Plastics Research Online (February 6, 2012) http://dx.doi.org/10.2417/ spepro.004061.

[10] Li J, Xie H. Synthesis of graphene oxide/polypyrrole nanowire composites for supercapacitors. Mater Lett, 78, 106 (2012). http:// dx.doi.org/10.1016/j.matlet.2012.03.013.

[11] Han Y, Hao L, Zhang X. Preparation and electrochemical performances of graphite oxide/polypyrrole composites. Synth Met, $\mathbf{1 6 0}$, 2336 (2010). http://dx.doi.org/10.1016/j.synthmet.2010.09.008.

[12] Liu Y, Chu Y, Yang L. Adjusting the inner-structure of polypyrrole nanoparticles through microemulsion polymerization. Mater Chem Phys, 98, 304 (2006). http://dx.doi.org/10.1016/j.matchemphys.2005.09.025.

[13] Kassim A, Basar Z, Mahmud HNME. Effects of preparation temperature on the conductivity of polypyrrole conducting polymer. J Chem Sci, 114, 155 (2002). http://dx.doi.org/10.1007/ BF02704308.

[14] Kaynak A, Beltran R. Effect of synthesis parameters on the electrical conductivity of polypyrrole-coated poly(ethylene terephthalate) fabrics. Polym Int, 52, 1021 (2003). http://dx.doi.org/10.1002/ pi.1195.

[15] Bufon CCB, Vollmer J, Heinzel T, Espindola P, John H, Heinze J. Relationship between chain length, disorder, and resistivity in polypyrrole films. J Phys Chem B, 109, 19191 (2005). http:// dx.doi.org/10.1021/jp053516j.

[16] Ferenets M, Harlin A. Chemical in situ polymerization of polypyrrole on poly(methyl metacrylate) substrate. Thin Solid Films, $\mathbf{5 1 5}$, 5324 (2007). http://dx.doi.org/10.1016/j.tsf.2007.01.008.

[17] Chandra V, Kim KS. Highly selective adsorption of $\mathrm{Hg} 2+$ by polypyrrole-reduced graphene oxide composite. Chem Commun, 47, 3942 (2011). http://dx.doi.org/10.1039/C1CC00005E.

[18] Chitte HK, Bhat NV, Walunj VE, Shinde GN. Synthesis of polypyrrole using ferric chloride $(\mathrm{FeCl} 3)$ as oxidant together with some dopants for use in gas sensors. J Sensor Tech, 1, 47 (2011). http:// dx.doi.org/10.4236/jst.2011.12007.

[19] Taunk M, Kapil A, Chand S. Chemical synthesis and low temperature electrical transport in polypyrrole doped with sodium bis(2ethylhexyl) sulfosuccinate. J Mater Sci, 22, 136 (2012). http:// dx.doi.org/10.1007/s10854-010-0102-2.

[20] Gu Z, Li C, Wang G, Zhang L, Li X, Wang W, Jin S. Synthesis and characterization of polypyrrole/graphite oxide composite by in situ emulsion polymerization. J Polym Sci B, 48, 1329 (2010). http://dx.doi.org/10.1002/polb.22031.

[21] Konwer S, Boruah R, Dolui S. Studies on conducting polypyrrole/ graphene oxide composites as supercapacitor electrode. J Electron Mater, 40, 2248 (2011). http://dx.doi.org/10.1007/s11664-0111749-z.

[22] Han J, Dai J, Zhou C. Guo R. Dilute cationic surfactant-assisted synthesis of polyaniline nanotubes and application as reactive support for various noble metal nanocatalysts. Polym Chem, 4, 313
(2013). http://dx.doi.org/10.1039/C2PY20536J

[23] Jiang J, Luo DM, Qian D. Electrochemical capacitive property of polypyrrole/graphene oxide composites. J Jishou Univ Nat Sci, 33, 93 (2012). http://dx.doi.org/10.3969/j.issn.1007-2985 2012.03.022.

[23] Unnikrishnan L, Madamana P, Mohanty S, Nayak SK. Polysulfone/C30B nanocomposite membranes for fuel cell applications: effect of various sulfonating agents. Polym Plast Tech Eng, 51, 568 (2012). http://dx.doi.org/10.1080/03602559.2012.654580.

[24] Zhang TY, Zhang D. Aqueous colloids of graphene oxide nanosheets by exfoliation of graphite oxide without ultrasonication. Bull Mater Sci, 34, 25 (2011). http://dx.doi.org/10.1007/ s12034-011-0048-x.

[25] Mudila H, Zaidi MGH, Rana S, Joshi V, Alam S. Enhanced electrocapacitive performance of graphene oxide polypyrrole nanocomposites. Int J Chem Anal Sci, 4, 139 (2013). http://dx.doi org/10.1016/j.ijcas.2013.09.001.

[26] Thakur S, Karak N. Green reduction of graphene oxide by aqueous phytoextracts. Carbon, 50, 5331 (2012). http://dx.doi.org/10.1016/ j.carbon.2012.07.023.

[27] Liu K, Li Y, Xu F, Zuo Y, Zhang L, Wang H, Liao J. Graphite/ poly (vinyl alcohol) hydrogel composite as porous ring skirt for artificial cornea. Mater Sci Eng C, 29, 261 (2009). http://dx.doi. org/10.1016/j.msec.2008.06.023.

[28] Qiao YS, Shen LZ, Dou T, Hu M. Polymerization and characterization of high conductivity and good adhension polypyrrole films for electromagnetic interference shielding. Chin J Polym Sci, 28, 923 (2010). http://dx.doi.org/10.1007/s10118-010-9175-x.

[29] Sonavane AC, Inamdar AI, Dalavi DS, Deshmukh HP, Patil PS. Simple and rapid synthesis of $\mathrm{NiO} / \mathrm{PPy}$ thin films with improved electrochromic performance. Electrochim Acta, 55, 2344 (2010). http://dx.doi.org/10.1016/j.electacta.2009.11.087.

[30] Chen W, Xue G. Formation of conducting polymer nanostructures with the help of surfactant crystallite templates. Front Mater Sci China, 4, 152 (2010). http://dx.doi.org/10.1007/s11706-010-0016-1.

[31] Qu B, Xu YT, Lin SJ, Zheng YF, Dai LZ. Fabrication of Pt nanoparticles decorated PPy-MWNTs composites and their electrocatalytic activity for methanol oxidation. Synth Met, 160, 732 (2010). http:// dx.doi.org/10.1016/j.synthmet.2010.01.012

[32] Zhao Y, Zhan L, Tian J, Nie S, Ning Z. Enhanced electrocatalytic oxidation of methanol on $\mathrm{Pd} /$ polypyrrole: graphene in alkaline medium. Electrochim Acta, 56, 1967 (2011). http://dx.doi org/10.1016/j.electacta.2010.12.005.

[33] Afanasov IM, Shornikova ON, Avdeev VV, Lebedev OI, Van Tendeloo G, Matveev AT. Expanded graphite as a support for Ni/carbon composites. Carbon, 47, 513 (2009). http://dx.doi.org/10.1016/j. carbon.2008.10.034

[34] El Achaby M, Arrakhiz FZ, Vaudreuil S, Essassi E, Qaiss MA. Piezoelectric $\beta$-polymorph formation and properties enhancement in graphene oxide: PVDF nanocomposite films. Appl Surf Sci, 258, 7668 (2012). http://dx.doi.org/10.1016/j.apsusc.2012.04.118.

[35] Wojtoniszak M, Chen X, Kalenczuk RJ, Wajda A, Łapczuk J, Kurzewski M, Drozdzik M, Chu PK, Borowiak-Palen E. Synthesis, dispersion, and cytocompatibility of graphene oxide and reduced graphene oxide. Colloids Surf B, 89, 79 (2012). http://dx.doi.org/ 10.1016/j.colsurfb.2011.08.026.

[36] Li S, Lu X, Xue Y, Lei J, Zheng T, Wang C. Fabrication of polypyrrole/graphene oxide composite nanosheets and their applications for $\mathrm{Cr}(\mathrm{VI})$ removal in aqueous solution. mailto:xflu@jlu.edu. 
cnPLoS One, 7, e43328 (2012). http://dx.doi.org/10.1371/journal. pone. 0043328 .

[37] Gudarzi MM, Sharif F. Enhancement of dispersion and bonding of graphene-polymer through wet transfer of functionalized graphene oxide. eXPRESS Polym Lett, 6, 1017 (2012). http://dx.doi. org/10.3144/expresspolymlett.2012.107.

[38] Luo YL, Fan LH, Xu F, Chen YS, Zhang CH, Wei QB. Synthesis and characterization of $\mathrm{Fe} 3 \mathrm{O} 4 / \mathrm{PPy} / \mathrm{P}(\mathrm{MAA}-\mathrm{co}-\mathrm{AAm})$ trilayered composite microspheres with electric, magnetic and $\mathrm{pH}$ response characteristics. Mater Chem Phys, 120, 590 (2010). http://dx.doi. org/10.1016/j.matchemphys.2009.12.002.

[39] Ramya R, Sangaranarayanan MV. Analysis of polypyrrole-coated stainless steel electrodes: estimation of specific capacitances and construction of equivalent circuits. J Chem Sci, 120, 25 (2008). http://dx.doi.org/10.1007/s12039-008-0004-5.

[40] Bose S, Kuila T, Uddin ME, Kim NH, Lau AKT, Lee JH. In-situ synthesis and characterization of electrically conductive polypyrrole/graphene nanocomposites. Polymer, 51, 5921 (2010). http:// dx.doi.org/10.1016/j.polymer.2010.10.014.

[41] Nie G, Qu L, Xu J, Zhang S. Electrosyntheses and characterizations of a new soluble conducting copolymer of 5-cyanoindole and 3,4-ethylenedioxythiophene. Electrochim Acta, 53, 8351 (2008). http://dx.doi.org/10.1016/j.electacta.2008.06.058. 